\title{
Wood decaying properties of the termite mushroom Termitomyces eurrhizus
}

\author{
Kazuko Ono $^{1} \cdot$ Toshimitsu Hata $^{1} \cdot$ Tsuyoshi Yoshimura $^{1} \cdot$ Kazuhiko Kinjo $^{2}$
}

Received: 26 April 2016/Accepted: 14 September 2016/Published online: 29 September 2016

(C) The Japan Wood Research Society 2016

\begin{abstract}
Four strains of the termite mushroom Termitomyces eurrhizus collected in Japan were surveyed for their wood decaying properties in three softwood and two hardwood species, in comparison with the white-rot fungus Trametes versicolor and the brown-rot fungus Fomitopsis palustris. All strains of T. eurrhizus degraded only the surfaces of the wood samples, and differences in mass-loss rates between heartwood and sapwood were generally not significant. Higher mass-loss rates were generally obtained in softwood than in hardwood. The results of chemical analyses of decayed wood samples indicated that $T$. eurrhizus does not have high lignin-degradation ability, even though it is categorized as a white-rot fungus. These results clearly suggest the unique physiological characteristics of T. eurrhizus.
\end{abstract}

Keywords Chemical analysis - Scanning electron microscope (SEM) - Termite mushroom - Wood decay test

\section{Introduction}

The fungi Termitomyces are known to have a unique life cycle. These fungi are distributed in tropical and subtropical areas from Africa to Southeast Asia [1], and are found only in nests of Macrotermitinae termites in the wild. They live in a medium called the fungus comb,

Kazuko Ono

onokazu@rish.kyoto-u.ac.jp

1 Research Institute for Sustainable Humanosphere, Kyoto University, Gokasho, Uji-Shi, Kyoto, Japan

2 Faculty of Agriculture, University of the Ryukyus, 1 Senbaru, Nishihara-cho, Nakagami-gun, Okinawa, Japan located in a special chamber, fungus garden, inside the nest. The termites collect plant materials from outside the nest to maintain the fungus combs, which they later eat [2]. The function of this symbiotic relation is still not clear, but some tentative theories have been proposed [3]: (1) Termitomyces is an additional protein-rich food source for the termites; (2) Termitomyces has a role in lignin degradation for the termites, facilitating their access to cellulose; (3) Termitomyces decreases the $\mathrm{C} / \mathrm{N}$ ratio of foraged plant materials by metabolizing carbohydrates; (4) Termitomyces provides cellulases and xylanases to work synergistically and/or complementarily with endogenous termite enzymes.

In Japan, two Termitomyces fungi have been reported from a region of Okinawa Prefecture, the southernmost tip of Japan [4-6]. These mushrooms have fruit bodies during a brief period at the end of the rainy season, and are not only edible but actually prized for their taste [7]. Thus, Termitomyces mushrooms have a potential market value in Japan, where wide variety of mushrooms is incorporated into the traditional cuisine, and where mushrooms are artificially cultivated. If artificial cultivation methods could be developed for these tasty mushroom species, they would likely find an appreciative audience in Japan. However, because of the symbiotic relationship with termites, there has been no report of the successful cultivation of these mushrooms under artificial conditions.

The only known host termite of Termitomyces fungi in Japan is Odontotermes formosanus [8, 9]. This subterranean termite is known as an important pest for agricultural crops, forest and timber constructions in Asia [10]. It is believed that $O$. formosanus collects various plant residues in the field to prepare the fungal media. Therefore, we consider that various plant materials can be used for the media of Termitomyces fungi. 
In this study, we surveyed the wood-decaying characteristics of four strains of Termitomyces eurrhizus. These strains were selected from twenty-seven strains collected in Okinawa Prefecture, Japan, for their rapid growth and easy handling [11]. The major aim of this study was to evaluate wood decaying ability of $T$. eurrhizus with some strains under the same culture condition. In addition, the feasibility of wood materials to artificial media was also discussed. It would also reveal some unknown relationships between host termites and Termitomyces. Among the five wood species used in the present study, Pinus densiflora is generally preferred by termites. Cryptomeria japonica and Chamaecyparis obtusa are dominant softwood plantation trees in Japan. Fagus crenata is commonly used in artificial cultivation of mushrooms in Japan. Finally, Quercus miyagii is a hardwood species distributed in the southern islands of Japan, where T. eurrhizus and O. formosanus are also present [12].

\section{Materials and methods}

\section{Fungal strains}

Four strains of Termitomyces eurrhizus (T3, T11, T25 and T26) were used in this study. They were collected in Okinawa Prefecture, Japan in 2004 and 2005, and isolated from fruit bodies. As controls, a white-rot fungus, Trametes versicolor (FFPRI 1030), and a brown-rot fungus, Fomitopsis palustris (FFPRI 0507), were also employed. These two strains were designated as decay test fungi according to the Japan Industrial Standard [13] (JIS K 1571-2010)

\section{Wood samples}

Heartwood and sapwood of three softwood species, Pinus densiflora, Cryptomeria japonica, and Chamaecyparis obtusa and one hardwood species, Fagus crenata, were employed for an eight-week decay test. C. obtusa is highest decay durability, followed by $C$. japonica, $P$. densiflora and $F$. crenata [14]. For the twelve-week decay test, heartwood and sapwood of the above four wood species and the hardwood Quercus miyagii were used. Wood species was same, but samples for the eight-week test were taken from different logs than samples for twelve-week test. The sample size was $10 \mathrm{~mm} \quad(\mathrm{R}) \times 10 \mathrm{~mm}$ $(\mathrm{T}) \times 5 \mathrm{~mm}(\mathrm{~L})$. This small size of samples was determined by the slow growth of T. eurrhizus, 1.1-1.2 mm/day on cellulose containing medium [15]. They were dried at $60{ }^{\circ} \mathrm{C}$ for 48 hours to determine the oven-dried weight before the tests according to the methods of JIS K 1571-2010 [13].

\section{Decay tests}

Fungal inoculums were prepared with potato dextrose agar (PDA; Nissui, Tokyo, Japan) plates. A seven-mm-diameter inoculum was taken from the plate, and was inoculated on $100 \mathrm{ml}$ of agar medium [glucose $4 \%$ (w/v), malt extract $1.5 \%(\mathrm{w} / \mathrm{v})$, peptone $0.3 \%(\mathrm{w} / \mathrm{v})$, agar $2 \%(\mathrm{w} / \mathrm{v})]$ in a 450-ml screw cap glass bottle. After the mycelia grew over the media surface, three test wood blocks were set on the mycelial mat. The bottle-caps were tightly sealed because T. eurrhizus is extremely sensitive to contamination, and then kept for eight or twelve weeks at $26{ }^{\circ} \mathrm{C}$ in the dark. After exposure, the mycelia that covered the samples were removed gently, and the samples were dried at $60{ }^{\circ} \mathrm{C}$ for 48 hours and weighed to determine the mass loss. The numbers of repetitions were six and nine for the eight- and twelve-week trials, respectively.

\section{Scanning electron microscopic (SEM) observation}

The eight-week decay samples were subjected to microscopic observation. The samples were dehydrated using a solvent displacement method by soaking in an ethanol series $[10,20,40,60,80,90$ and $100 \%$ (v/v)], acetone and pentane for 10 minutes, respectively. Each sample was sliced with a fresh razor and coated with gold for observation under a SEM (JSM-5310; JEOL, Tokyo, Japan) at $10 \mathrm{kV}$. Both surfaces and core portions of the samples were observed (Fig. 1).

\section{Chemical analyses}

For chemical analyses, twelve-week decay samples were ground into 40-mesh-pass size by a high-speed blender (VM0113; Vitamix, Cleveland, OH). Lignin content was determined by the Klason method [16]. Using the filtrates from the Klason lignin analysis, holocellulose was quantitated as a total sugar by the phenol-sulfuric acid method

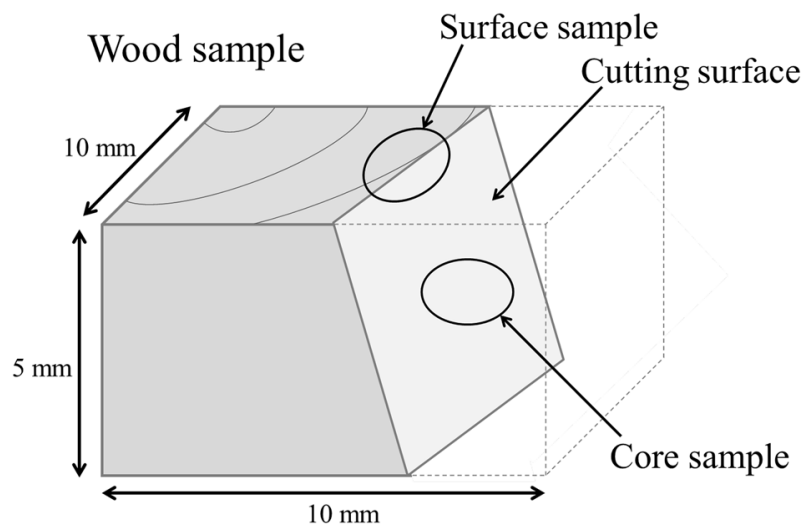

Fig. 1 Objects of SEM observation 
[17]. Glucose was used as a standard. The lignin decrease rates (LDRs) and total sugar decrease rates (SDRs) were calculated from these results using the following pair of equations:

$\mathrm{LDR}=\left[L_{1}-(100-\mathrm{MLR}) / 100 \times L_{2}\right] / L_{1} \times 100$

where $L_{1}$ is the average lignin content of sound wood samples $(n=3), L_{2}$ is the lignin content of the individual decayed wood sample, and MLR is the mass-loss rate of the sample, and

$\mathrm{SDR}=\left[S_{1}-(100-\mathrm{MLR}) / 100 \times S_{2}\right] / S_{1} \times 100$

where $S_{1}$ is the average total sugar content of sound wood samples $(n=3), S_{2}$ is the total sugar content of the individual decayed wood sample, and MLR is the mass-loss rate of the sample.

\section{Statistical analysis}

The mass-loss rates (MLRs) of the decay tests, LDRs and SDRs were analyzed using analysis of variance (ANOVA) and Tukey-Kramer tests $(p<0.05)$.

\section{Results}

\section{Eight-week decay test}

The MLRs of the wood samples after the 8-week decay tests are displayed in Table 1.

In the heartwood of $P$. densiflora, there were no significant difference in MLRs between the strains of $T$. eurrhizus and the control strain $T$. versicolor, with the exception of T25. T25 showed lower MLRs in both heartwood and sapwood than those of the other $T$. eurrhizus strains. In all the T. eurrhizus strains, the MLRs of sapwood (8.7, 7.6, 6.0 and $8.3 \%$ ) were significantly higher than those of heartwood $(6.7,6.6,3.5$ and $6.8 \%)$.

There was a wide variety in the strains of T. eurrhizus regarding decay in the heartwood of $C$. japonica. The MLR by T11 $(10.1 \%)$ was not significantly different from that of T. versicolor, which had the highest rate $(11.5 \%)$. Meanwhile, T25 showed the lowest MLR (4.4\%), and those of T3 and T26 were not significantly different. The MLR of T26 (5.6\%) was not significantly different from that of the brown-rot fungus $F$. palustris $(8.0 \%)$. In sapwood, $T$. eurrhizus exhibited lower MLRs than those of $T$. versicolor and $F$. palustris. In addition, T11 and T25 did not display a significant difference in MLRs between heartwood and sapwood. However, T3 and T26 showed lower MLRs in heartwood than in sapwood.

The various strains of Termitomyces eurrhizus also showed a variety of MLRs for heartwood of C. obtusa. T11 had the highest MLR (10.2\%), while T25 had the lowest MLR (5.2\%). There was no significant difference between the MLRs of T25 and F. palustris (5.2\%), but both were significantly lower than the MLRs of the other 3 strains. In sapwood, two strains (T3 and T26; 11.7 and $12.0 \%$, respectively) showed no significant difference from $T$. versicolor $(14.5 \%)$ and other 2 strains (T11 and T25; 8.7 and $7.2 \%$ ) showed lower than $T$. versicolor. All the strains had lower MLRs than that of $F$. palustris $(21.1 \%)$.

In the case of the hardwood $F$. crenata, all strains of $T$. eurrhizus showed unexpected results. This wood is known to be susceptible to decay fungi [18], yet the MLRs of the 4 strains were 2.3, 2.3, 0.9 and $2.4 \%$ in heartwood, and 5.3, 3.7, 3.2 and $4.7 \%$ in sapwood, respectively. These values were significantly lower than those of the two control fungi, $T$. versicolor and $F$. palustris, in both heartwood (15.3 and $8.5 \%)$ and sapwood (17.9 and 15.2\%).

In this test, strain T25 showed the lowest MLRs in all wood samples with the exception of $P$. densiflora sapwood. In many cases, the MLRs of T. eurrhizus in sapwood were higher than those of heartwood, and in some cases, there was no significant difference in MLRs between heartwood and sapwood.

\section{Twelve-week decay test}

The MLRs in twelve-week decay tests are also shown in Table 1. In all test bottles, the mycelia of strain T25 died before finishing the test period; therefore, the results in T25 were omitted.

For $P$. densiflora, all fungi showed similar MLRs in the heartwood; in the sapwood; only T11 had lower MLR $(4.8 \%)$ than the others. T11 had a lower MLR in sapwood than in heartwood, but the others showed no significant difference between heartwood and sapwood.

For $C$. japonica heartwood, T11 had a significantly lower MLR $(1.1 \%)$ than the other 2 strains of T. eurrhizus (2.2 and $4.9 \%$ ). All T. eurrhizus strains showed lower MLRs than that of $F$. palustris $(9.4 \%)$, but there was no significant difference from that of $T$. versicolor. T26 $(8.4 \%)$ showed no significant difference from $F$. palustris $(9.9 \%)$ in sapwood, and both were higher than those of the other strains. The MLRs of T3 and T11 were not significantly different between heartwood and sapwood, but the MLR of T26 in heartwood was significantly lower than that in sapwood.

In $C$. obtsa heartwood, T26 showed a significantly higher MLR $(10.2 \%)$ than all the other test fungi. There was no significant difference in the MLRs of T3 $(7.0 \%)$ and T11 $(7.7 \%)$, T11 and $F$. palustris $(8.6 \%)$, respectively. In sapwood, T26 had a higher MLR (10.0\%) than the other $T$. eurrhizus strains (7.9 and $6.4 \%)$. In addition, T26 and the control fungi did not have significantly 
Table 1 Mass-loss rates of 4 wood samples after eight-week decay tests and five wood samples after twelve-week decay tests

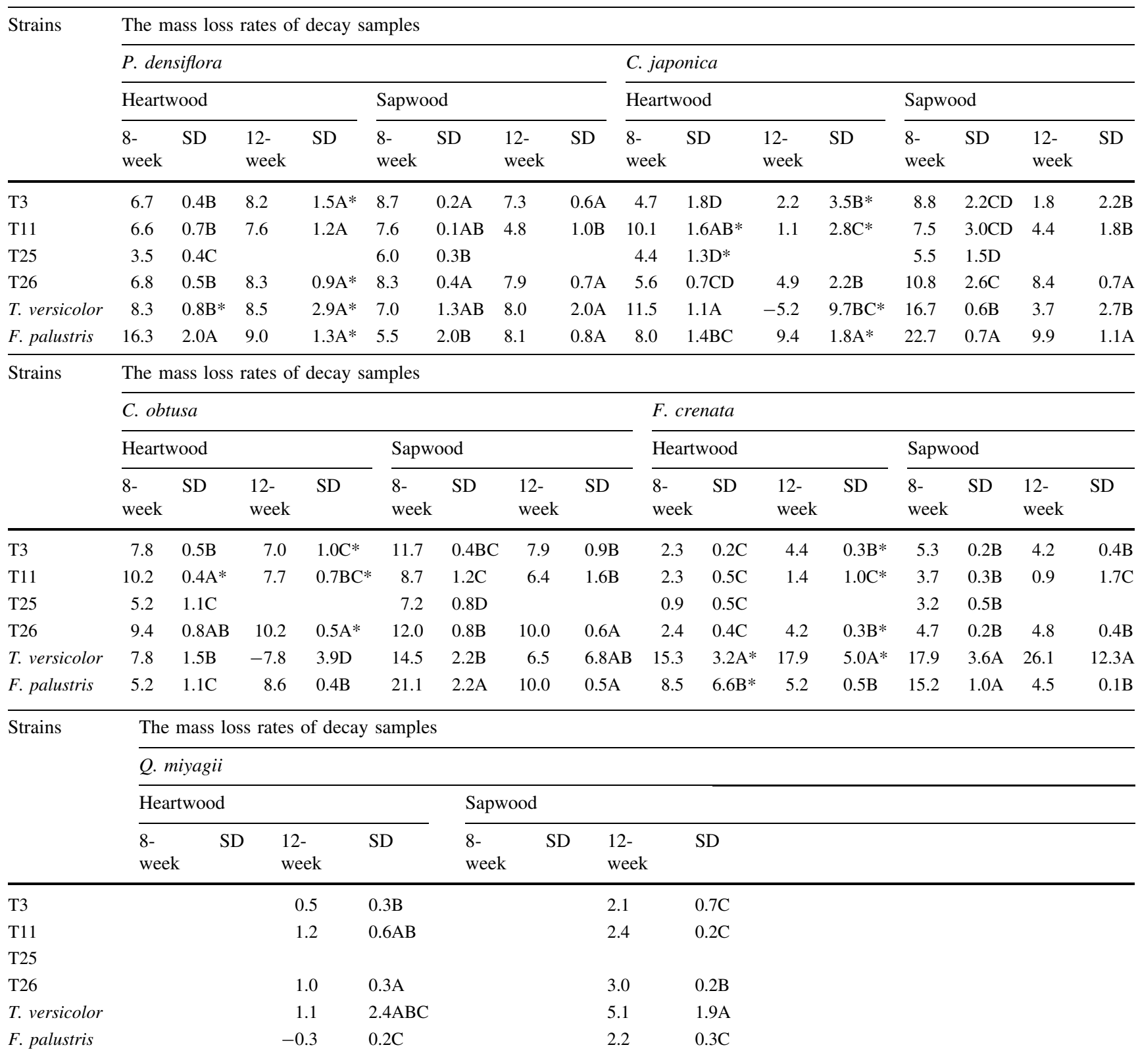

The same characters indicate no significant difference by Tukey-Kramer test $(p>0.05)$

The samples for the 8-week test were taken from different logs with samples for 12-week test

The mass-loss rates for 8-week decayed samples cannot be compared with those for 12-week decayed ones

$S D$ standard deviation of mass-loss rate

* There was no significant difference between heartwood and sapwood ( $t$-test $p>0.05)$

different MLRs. No T. eurrhizus strains showed a significant different in MLRs between heartwood and sapwood.

In the heartwood and sapwood of $F$. crenata, the MLRs in T3 $(4.4,4.2 \%)$ and T26 (4.2, $4.8 \%)$ were significantly lower than those of $T$. versicolor $(17.9,26.1 \%)$, but they were not significantly different from those of $F$. palustris $(5.2,4.5 \%)$, while the MLRs of T11 (1.4, $0.9 \%)$ were significantly lower than those of the other fungi. There was no significant difference between heartwood and sapwood MLRs for any T. eurrhizus strain. 
All the fungi showed the lower MLRs for the heartwood of $Q$. miyagii than for other wood species. Three T. eurrhizus strains showed low MLRs (0.5, 1.2 and $1.0 \%)$, without any significant difference from that of $T$. versicolor (1.1\%). In contrast, for sapwood, T. versicolor had a higher MLR $(5.1 \%)$ than those of the T. eurrhizus strains (2.1, 2.4 and $3.0 \%$ ). All T. eurrhizus strains displayed significantly lower MLRs in heartwood than in sapwood.

\section{SEM observation}

In this observation, wood samples decayed by the white-rot fungus $T$. versicolor were employed as comparative control, because Termitomyces fungi are classified as white-rot fungi [19]. The observation positions in the sample are indicated in Fig. 1. The results of SEM observations are shown in Figs. 2, 3, 4, 5.

In all samples exposed to $T$. versicolor, there were many mycelia in almost all tracheids and vessels, with serious decay symptoms (P. densiflora, Fig. 2 A-B; C. japonica, Fig. 3a, b; C. obtusa, Fig. 4a, b; and F. crenata, Fig. 5a, b). However, mycelia of $T$. eurrhizus were rarely found in the tracheids of softwood (P. densiflora, Fig. 2c, d; C. japonica, Fig. 3c, d; and C. obtusa, Fig. 4c, d). Additionally, there were no decay symptoms around the mycelia at all. In $F$. crenata, the mycelia of $T$. eurrhizus were found inside vessels in the hardwood more frequency than tracheids in softwood (Fig. 5c, d), but no decay symptoms were observed. In addition, there were no mycelia in other woody tissues, such as xylem rays and fibers. There were many $T$. eurrhizus mycelia covering the sample surfaces and edges (P. densiflora, Fig. 2e, f; C. japonica, Fig. 3e, f; C. obtusa, Fig. 4e, f; and F. crenata, Fig. 5e, f).

\section{Component analyses}

LDRs and SDRs of 3 T. eurrhizus strains (T3, T11 and T26), T. versicolor and $F$. palustris are shown in Tables 2 and 3 , respectively.

There was no significant difference among all fungal strains in either the LDRs or the SDRs of heartwood and sapwood for P. densiflora (Tables 2, 3).

In $C$. japonica, none of the strains showed any significant difference in LDRs between the heartwood and sapwood samples (Table 2). They also showed no difference in SDRs in the heartwood of $C$. japonica. In the sapwood, there was no significant difference in SDRs among the three $T$. eurrhizus strains and $T$. versicolor. T3 exhibited a significantly lower SDR than that of $F$. palustris, but the other two strains showed no significant difference from $F$. palustris (Table 3 ).

Interestingly, all the fungi exhibited negative LDRs in heartwood of C. obtusa, and T3 and T11 also showed negative LRDs in sapwood (Table 2). LDRs of all the fungal strains were not significantly different in sapwood. It is suggested that T. eurrhizus has low lignin degradation ability in C. obtusa. In heartwood, the SDRs of T11 and T26 were not significantly different from that of $F$. palustris; in sapwood, only the SDR of T26 was not significantly different from that of $F$. palustris (Table 3 ). With respect to the LDRs and the SDRs of C. obtusa, there was no significant difference among $T$. eurrhizus strains.

In the heartwood of $F$. crenata, the LDRs of T3 and T11 were significantly lower than that of $T$. versicolor, while the LDR of T26 was not significantly different. On the other hand, the LDRs of all the T. eurrhizus strains were significantly lower than that of $T$. versicolor in sapwood. The SDRs in heartwood of all fungal strains were not significantly different. But, in sapwood, the SDR of T11 was significantly lower than that of $F$. palustris.

Lignin degradation of $Q$. miyagii was not significantly different among all the fungal strains in heartwood, and in sapwood, the only significant difference was significantly lower LDR in T11 compared to $T$. versicolor. In heartwood, no fungal strains had significantly different SDRs. T26 did exhibit a significantly higher SDR than those of other T. eurrhizus strains in sapwood, but it was not significantly different from that of $F$. palustris.

\section{Discussion}

Regardless of wood species and sample location, all T. eurrhizus strains showed similar mass losses after eight-week exposure. The results suggested that $T$. eurrhizus can degrade heartwood as well as sapwood. Heartwood generally exhibits higher durability than that of sapwood, because heartwood has more extractives than that in sapwood. T. eurrhizus may have some resistance to extractives. We propose that a mixture of heartwood and sapwood may be used as a medium for artificial cultivation of $T$. eurrhizus, e.g., a whole small log produced by forest thinning.

From the results of eight-week decay test, T25 showed the lowest values of MLRs in all wood species both heartwood and sapwood. This strain has low degradation potential of wood. On the other hand, T26 showed the highest MLRs both decay tests in most of wood species. T26 is comparatively high wood degradation ability among four strains.

Meanwhile, the LDRs of T. eurrhizus were not significantly different from that of the brown-rot fungus $F$. palustris. Since brown-rot fungi generally decompose little lignin [20], this might indicate that $T$. eurrhizus has low lignin degradation ability. Termitomyces fungi are symbionts of Macrotermitinae termites, and one of the roles of the fungi is thought to be decomposition of lignin for termite digestion [21]. Other scientists have reported that the 

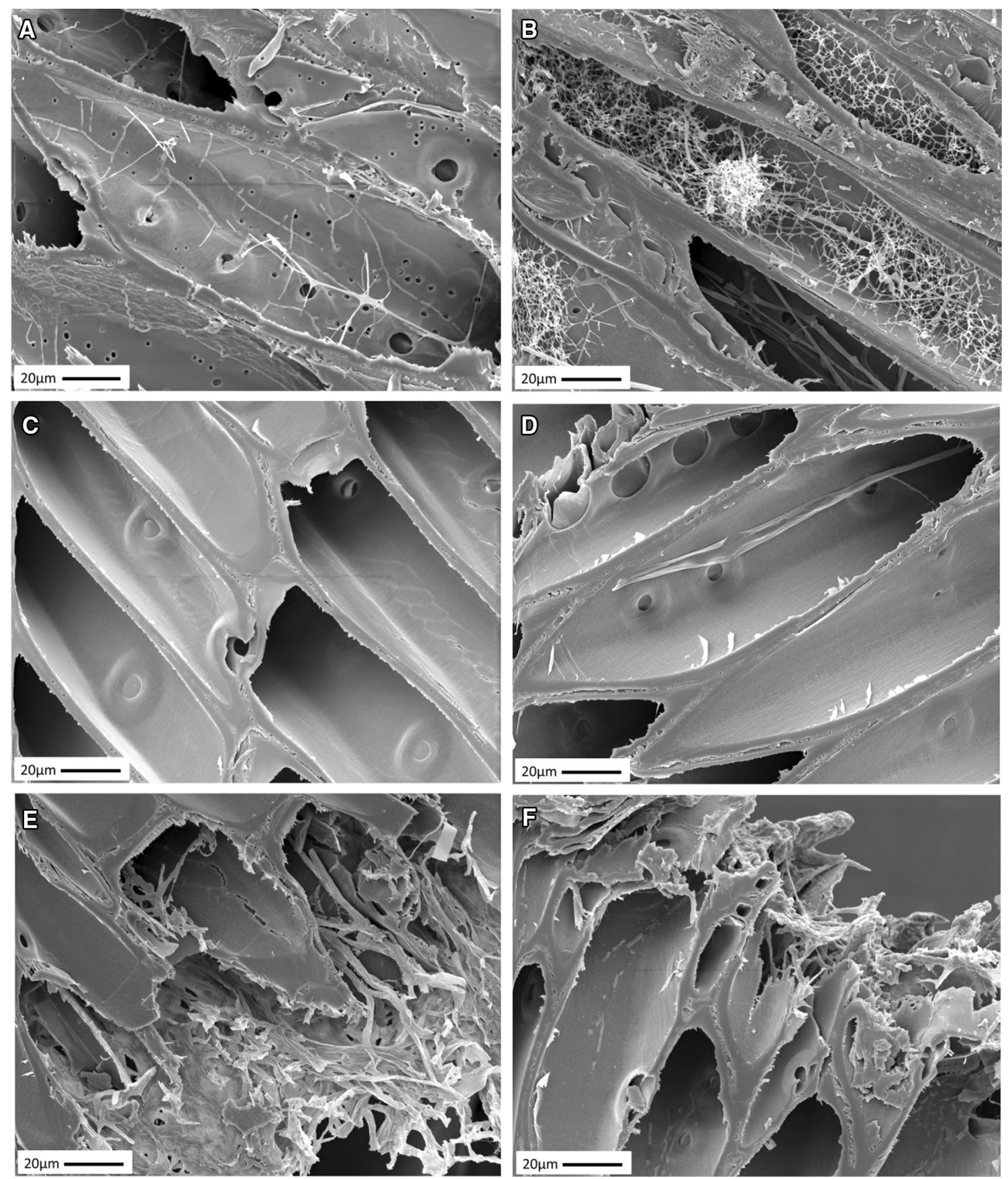

Fig. 2 SEM images of decayed wood samples of Pinus densiflora. a Heartwood core sample decayed by T. versicolor (FFPRI1030). b Sapwood core sample decayed by $T$. versicolor (FFPRI1030). c Heartwood core sample decayed by T. eurrhizus (T3). d Sapwood

core sample decayed by T. eurrhizus (T26). e The surface of a heartwood sample decayed by T. eurrhizus (T11). f The surface of a sapwood sample decayed by T. eurrhizus (T3)

roles of symbiotic fungi are unclear and differ depending on their host termites [22, 23]. The host termite Odontotermes formosanus in Japan might not depend on high lignin degradation by T. eurrhizus. The lignin contents of the fungus comb collected in Japan were 3-10\% [24], significantly lower than those of plants. Odontotermes formosanus may collect lignin-decomposed material for the comb. Alternatively, Xylaria fungi are known to settle

in fungus combs of Macrotermitinae termites [7, 25, 26]. Xylaria species have a solitary habit and the ability to degrade lignin [27]. Hence, the lignin of the comb may be decomposed by these Xylaria fungi. The termites are also known to feed on the fungal nodules, balls of Termitomyces mycelia, on the fungus comb [3]. T. eurrhizus is likely to be a source of protein for $O$. formosanus. Although we found wide variation in the SDRs, those of T. eurrhizus and 

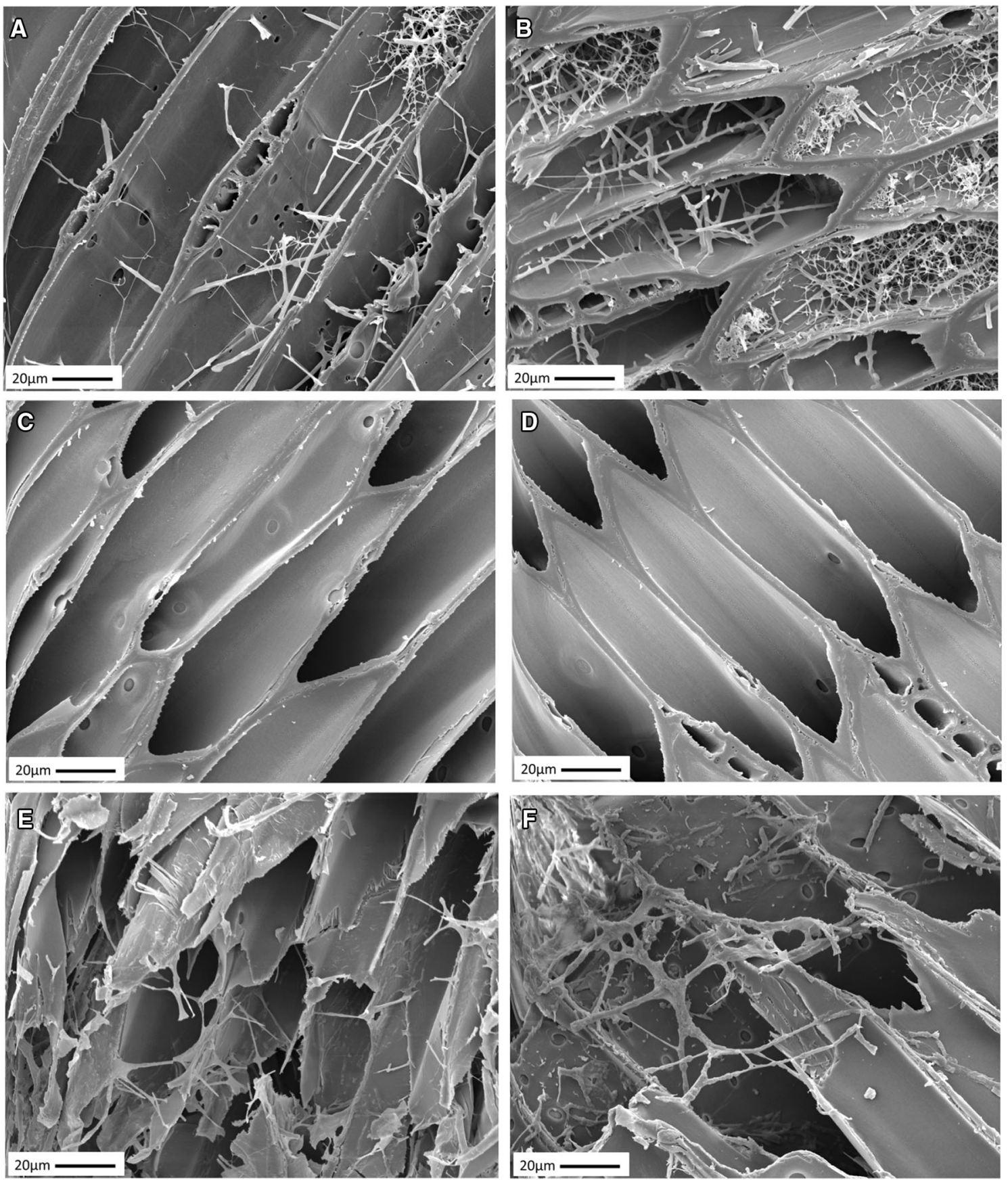

Fig. 3 SEM images of decayed wood samples of Cryptomeria japonica. a Heartwood core sample decayed by $T$. versicolor (FFPRI1030). b Sapwood core sample decayed by T. versicolor (FFPRI1030). c Heartwood core sample decayed by T. eurrhizus (T3).

d Sapwood core sample decayed by T. eurrhizus (T11). e The surface of a heartwood sample decayed by T. eurrhizus (T26). f The surface of a sapwood sample decayed by T. eurrhizus (T25)

control fungi were not significantly different. It might indicate the similar degradation abilities of T. eurrhizus to holocellulose. Our previous study indicated that $T$. eurrhizus could grow sufficiently on cellulose-containing medium as a carbon-source [15].

In general, $F$. crenata is known to be susceptible to wood-decaying fungi, and is used in the cultivation of mushrooms in Japan [28]. But our T. eurrhizus strains induced little decay in either the 8- or the 12-week exposure. In addition, these strains also could not degrade $Q$. miyagii. These two species belong to the family Fagaceae. Fagaceae has tannin (0.2-8.8 \%) in wood [29], and tannin was reported to inhibit fungal decomposition [30]. Tannin could inhibit wood degradation of T. eurrhizus. Timbers of 

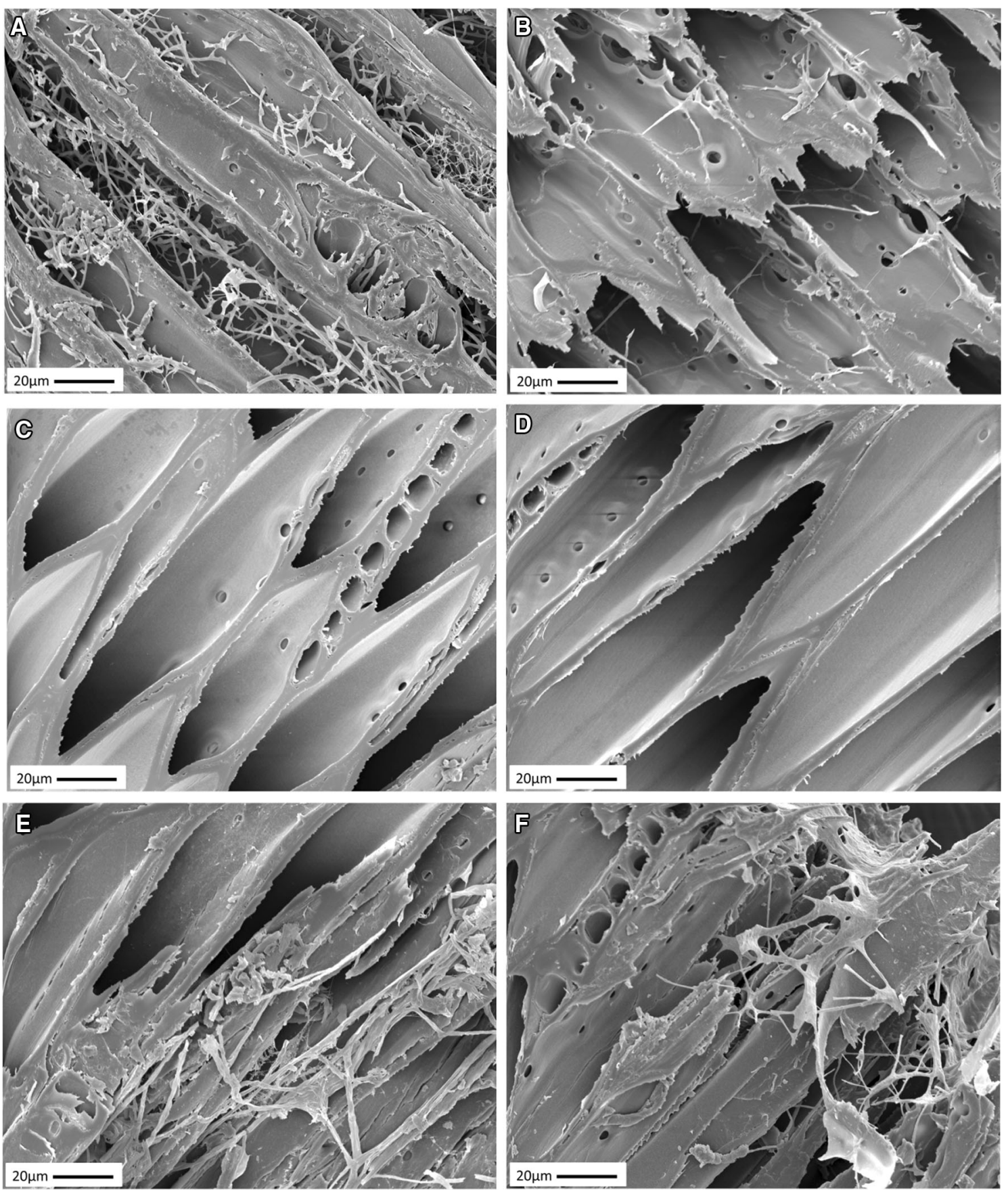

Fig. 4 SEM images of decayed wood samples of Chamaecyparis obtusa. a Heartwood core sample decayed by $T$. versicolor (FFPRI1030). b Sapwood core sample decayed by T. versicolor (FFPRI1030). c Heartwood core sample decayed by T. eurrhizus

Q. miyagii have been known as hard and durable materials since early times [31, 32]; the heartwood is especially known for its high decay durability.

Since T25 did not survive through the end of the test period of twelve weeks, T. eurrhizus might be unfit for long-term cultivation on artificial media. This was supported by the results that the MLRs of T3, T11 and
(T25). d Sapwood core sample decayed by T. eurrhizus (T26). e The surface of a heartwood sample decayed by T. eurrhizus (T11). f The surface of a sapwood sample decayed by T. eurrhizus (T26)

T26 after twelve weeks were the same as those of the eight-week tests. We incubated all the bottles hermetically because $T$. eurrhizus seemed to be sensitive to bacterial and fungal contamination in our preliminary experiments (Ono, unpublished data). On the other hand, the nests of the host termites are well ventilated $[33,34]$. Fungus combs have a sponge-like appearance 

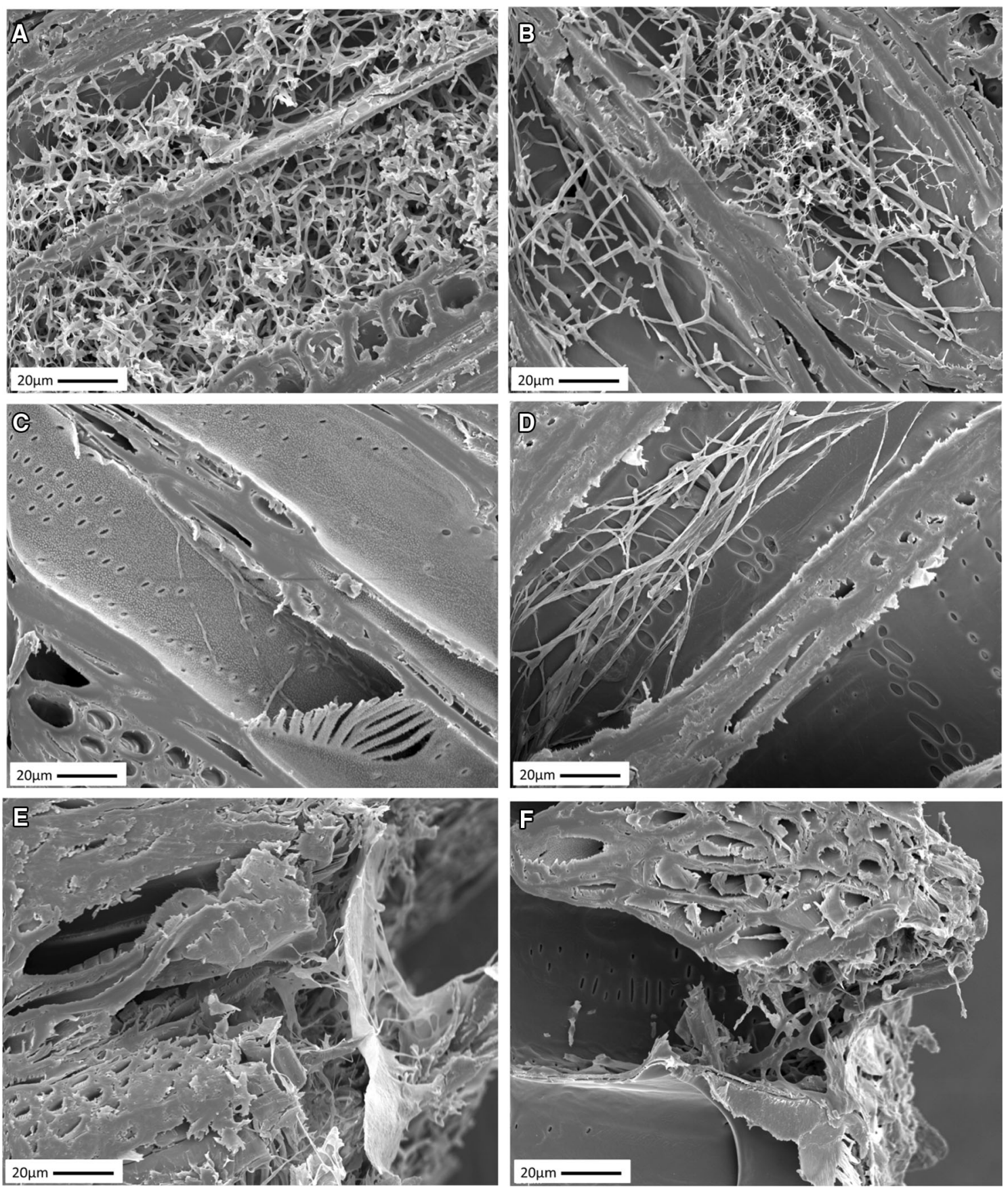

Fig. 5 SEM images of decayed wood samples of Fagus crenata. a Heartwood core sample decayed by T. versicolor (FFPRI1030). b Sapwood core sample decayed by $T$. versicolor (FFPRI1030). c Heartwood core sample decayed by T. eurrhizus (T11). d Sapwood

core sample decayed by T. eurrhizus (T3). e The surface of a heartwood sample decayed by T. eurrhizus (T3). $\mathbf{f}$ The surface of a sapwood sample decayed by T. eurrhizus (T11)

with a large surface area, meaning that Termitomyces fungi may prefer a well-ventilated condition. Moreover, fungus combs are fed from the bottom, and are maintained by termites by adding fresh media $[2,35]$. It is assumed that some metabolic products by the fungus might be stored in the agar media, and inhibit the growth of T. eurrhizus.

The results of SEM observation clearly showed that the mycelia of $T$. eurrhizus could not penetrate even the smaller wood blocks $[1 \mathrm{~cm}(\mathrm{R}) \times 1 \mathrm{~cm}(\mathrm{~T}) \times 0.5 \mathrm{~cm}(\mathrm{~L})]$. It is presumed that $T$. eurrhizus can only decay the surfaces of the samples. Wood materials of small particle size such as saw-dust are strongly recommended for the artificial media. However, mycelia of T. eurrhizus were often found 


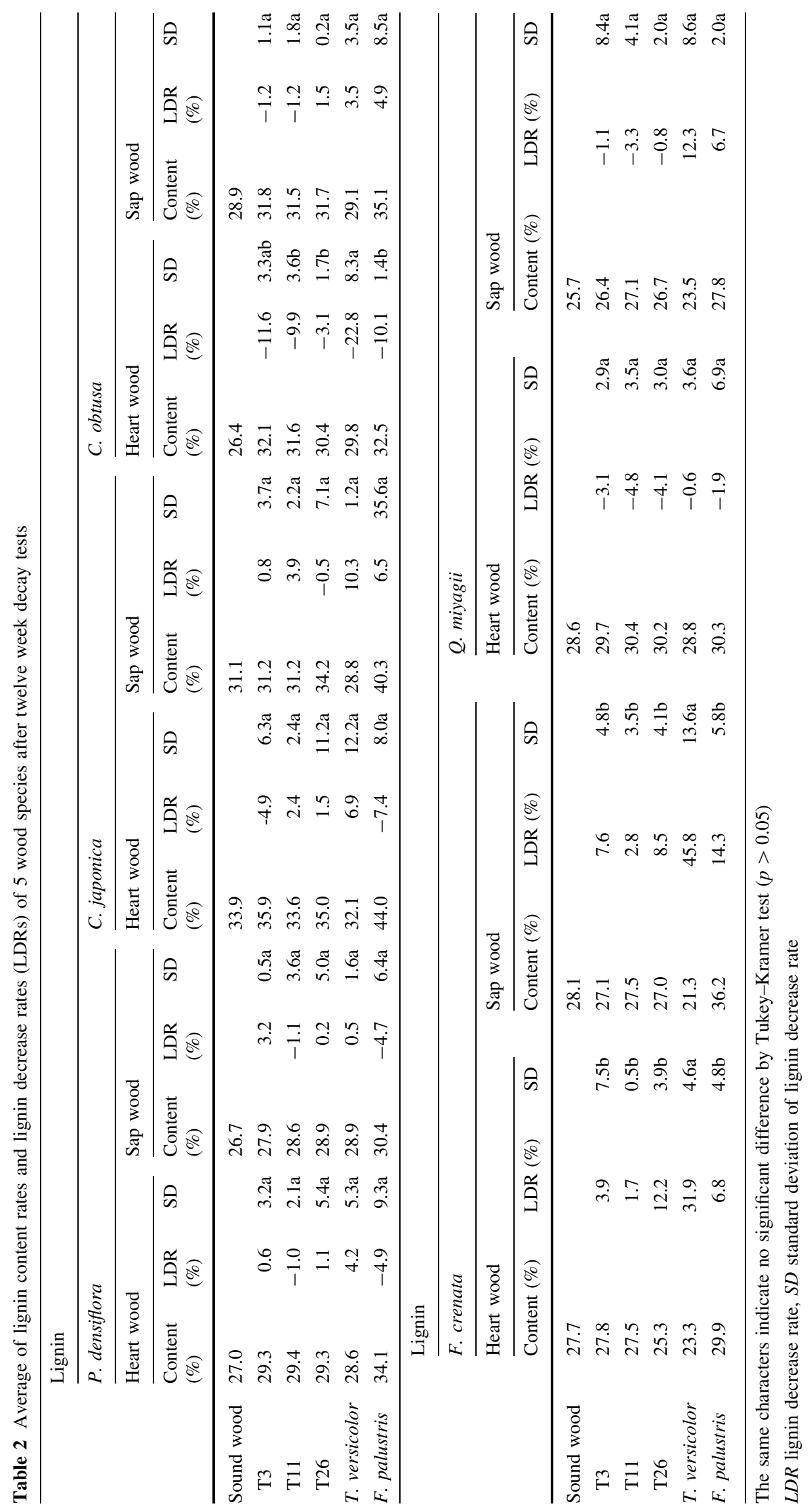




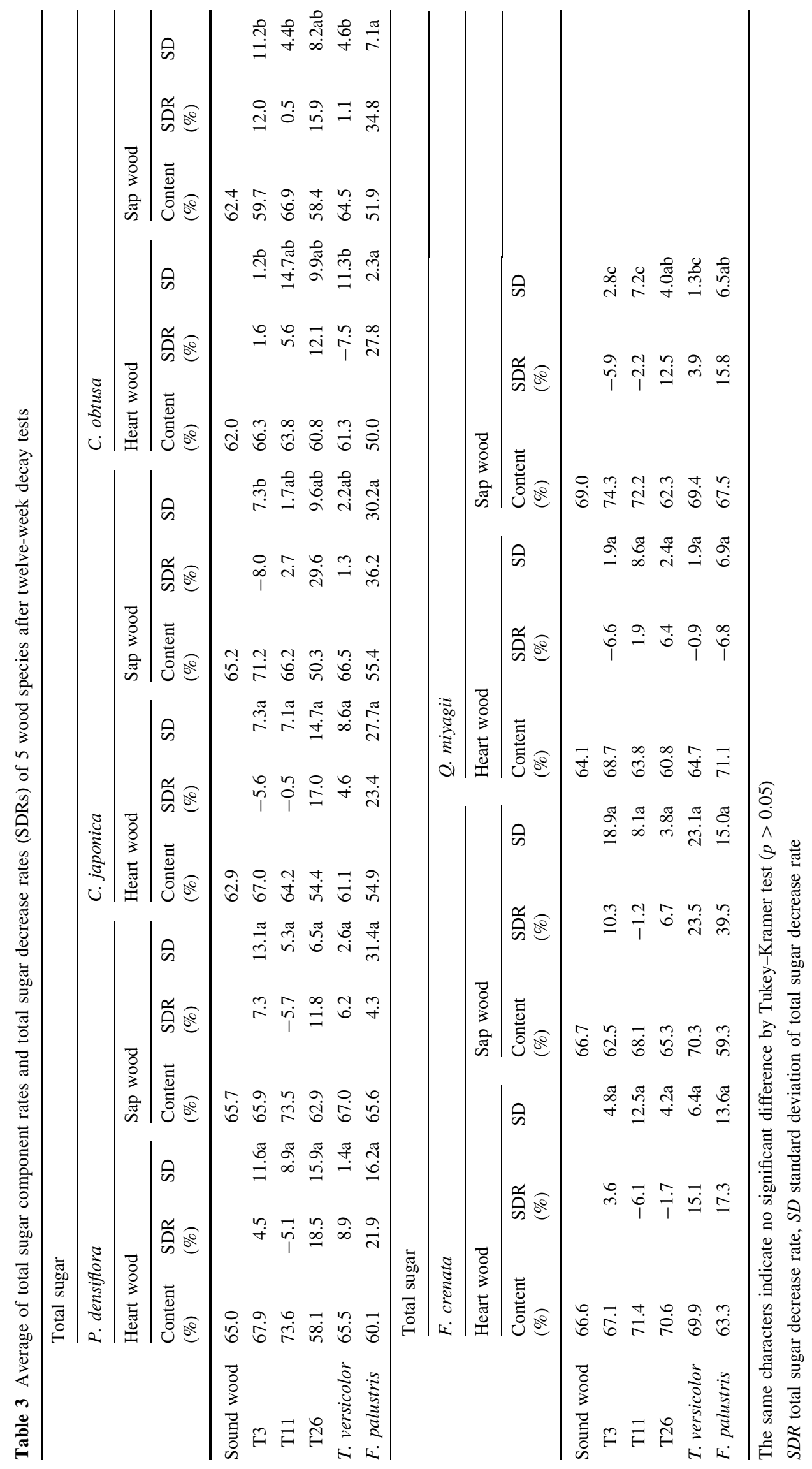


in the vessels of $F$. crenata. The size of vessels of $F$. crenata is larger than those of the softwood tracheids (Figs. 2-5). If the mycelia of T. eurrhizus prefer a wellventilated condition, they might not penetrate deep into tracheids.

This study shows that $T$. eurrhizus collected in Japan does not have high lignin-degradation ability. The low lignin content wood species may be favorable to $T$. eurrhizus. In addition, the fungus can only decay the surfaces of wood block samples. There is a possibility that the fungus prefers softwood to hardwood, suggesting that in the future artificial cultivation with forest-thinning resource such as Japanese cedar ( $C$. japonica) and cypress $(C$. obtusa) would be targeted. The presence of extractives might be one of factors relating to from this phenomenon.

Acknowledgments We would like to give special thanks to Mr. Akio Adachi, RISH, Kyoto University, for preparing wood specimens.

\section{References}

1. Aanen DK, Eggleton P (2005) Fungus-growing termites originated in African rain forest. Curr Biol 15:851-855

2. Otani Y (1992) The fungi grown with termites (in Japanese). Shiroari 90:3-10

3. Nobre N, Rouland-Lefèvre C, Aanen DK (2011) Comparative biology of fungus cultivation in termites and ants. In: Bignell DE, Roisin Y, Lo N (eds) Biology of termites: a modern synthesis. Springer, Dordrecht, pp 193-210

4. Otani Y (1979) Termitomyces albuminosus (Berk.) Heim collected in Ishigaki Island of Ryukyu archipelago Japan (in Japanese). Trans Mycol Soc Japan 20:195-202

5. Otani Y, Shimizu D (1981) Termitomyces clypeatus Heim collected from Iriomote Island, Okinawa, Japan (in Japanese). Bull Natn Sci Mus Tokyo Ser B 7(4):131-134

6. Kinjo K, Anucha P, Miyagi T (2005) Termitomyces eurrhizus collected from the main island of Okinawa (in Japanese). Trans Mycol Soc Japan 46:41-44

7. Otani Y (1982) The fungi grown with termites (in Japanese). Iden 36(12):8-12

8. Ikehara S (1966) Distribution of termites in the Ryukyu Archipelago (in Japanese). Bull Art Sci Univ Ryukyus (Math \& Nat Sci) 9:49-176

9. Yasuda I, Nakasone Y, Kinjo K, Yaga S (2000) Morphology and distribution of termites in Ryukyu Islands and north and south Daito Islands (in Japanese). Jpn J Ent (N S) 3:139-156

10. Huang Q-Y, Lei C-L, Xue D (2006) Field evaluation of a fipronil bait against subterranean termite Odontotermes formosanus (Isoptera: Termitidae). J Econ Entomol 99:455-461

11. Ono K, Yoshimura T, Kinjo K (2015) Screening of strains and media of Termitomyces eurrhizus collected from Japan toward nutritional analyses. The 6th international conference on sustainable future for human security 2015 (Oral), Bali, Indonesia, 17-19 November 2015

12. Kitamura S, Murata G (1979) Okinawa-urajirogashi (in Japanese). In: Colored illustrations of woody plants of Japan vol.II. Hoikusha Publishing, Osaka, pp 274-275

13. JIS K1571-2010 (2010) Test methods for determining the effectiveness of wood preservatives and their performance requirements (in Japanese). Japanese Standard Association, Tokyo
14. Meguro T (1997) Decay durability of timber (in Japanese). In: Yaga Y, Kawachi S, Imamura Y (eds) Wood science series 12 Preservation \& durability. Kaiseisha, Otsu, pp 79-82

15. Ono K, Yoshimura T, Kinjo K (2015) Effects of carbohydrate substrates on vegetative mycelial growth of Termitomyces eurrhizus from Okinawa Prefecture. Mushroom Sci Biotechnol 22:169-171

16. Dence CW (1994) Quantitative determination of lignin (in Japanese). In: Lin SY, Dence CW (eds) Methods in lignin chemistry. Uni Press, Tokyo, pp 21-25

17. Hodge JE, Hofreiter BT (1962) Phenol-sulfuric acid colorimetric method. In: Whisler RL, Wolfrom ML (eds) Methods in carbohydrate chemistry I: analysis and preparation of sugars. Academic Press, New York, pp 388-389

18. Takahashi M (1989) Decay durability of important timbers (in Japanese). Mushroom and wood. Tsukiji Shokan Publishing, Tokyo, pp 73-76

19. Bignell DE (2000) Introduction to symbiosis. In: Abe T, Bignell DE, Higashi M (eds) Termites: evolution, sociality, symbioses, ecology. Kluwer Academic Publishers, Dordrecht, pp 189-208

20. Takahashi M (1993) Biology of brown-rot fungi (in Japanese). Mokuzai Hozon 19:2-12

21. Hyodo F, Inoue T, Azuma J-I, Tayasu T, Abe T (2000) Role of the mutualistic fungus in lignin degradation in the fungusgrowing termites (Macrotermitinae: Isoptera). Soil Biol Biochem 32:653-658

22. Rouland C, Lenoir F, Lepage M (1991) The role of the symbiotic fungus in the digestive metabolism of several species of fungusgrowing termites. Comp Biochem Physiol 99A:657-663

23. Hyodo F, Tayasu I, Inoue T, Azuma J-I, Kudo T (2003) Different role of symbiotic fungi in lignin degradation and food provision for fungus-growing termites (Macrotermitinae: Isoptera). Funct Ecol 17:186-193

24. Kinjo K (2000) The mushroom cultivated by termite (in Japanese). Shinrin Kagaku 30:20-25

25. Rogers JD, Ju Y-M, Lehmann J (2005) Some Xylaria species on termite nests. Mycologia 94:914-923

26. Visser AA, Ros VID, De Beer ZW, Debets AJM, Hartog E, Kuyper TW, Læssøe T, Slippers B, Aanen DK (2009) Levels of specificity of Xylaria species associated with fungus-growing termites: a phylogenetic approach. Mol Ecol 18:553-567

27. Osono T, Takeda H (2001) Effects of organic chemical quality and mineral nitrogen addition on lignin and holocellulose decomposition of beech leaf litter by Xylaria sp. Eur J Soil Biol 37:17-23

28. Koide H (2001) The repertoire of mushroom and the basis of cultivation (in Japanese). In: Ohmori S, Koide H (eds) The complete of mushroom cultivation. Rural Culture Association Japan, Tokyo, pp 29-42

29. Mokuzai-Kogyo handbook 3rd edition (1982) Wood chemical property (in Japanese). Maruzen Publishing, Tokyo, p 133-174

30. Harrison AF (1971) The inhibitory effect of oak leaf litter tannnins on the growth of fungi, in relation to litter decomposition. Soil Biol Biochem 3:167-172

31. Nakama Y, Purves JM, Chen B (2013) Modern Japanese \& English translations and content analyses of 'The scope of the bureau of forest administration' from the 'Eight volumes on forest administration'. Sci Bull Agri Univ Ryukyus 60:45-58

32. Fujita S (1990) Some mechanical properties and utilization in Kiruki, Inosugi and Okinawa-urajirogashi wood (in Japanese). Bull Agri Kagoshima Univ 40:193-199

33. Turner JS (1994) Ventilation and thermal constancy of a colony of a southern African termite (Odontotermes transvaalensis: Macrotermitinae). J Arid Environ 28:231-248

34. Korb J (2003) Thermoregulation and ventilation of termite mound. Naturwissenschaften 90:212-219

35. Okuma M (2003) Termite symbiotic systems: efficient bio-recycling of lignocellulose. Appl Microbiol Biotechnol 61:1-9 